\title{
Rotating Machines Based Islanding Detection Using Fuzzy Logic Method Analysis
}

\author{
Lucas Ongondo Mogaka ${ }^{1}$, D. K. Murage ${ }^{2}$, Michael Juma Saulo ${ }^{1}$ \\ ${ }^{1}$ Electrical and Electronics Department, Technical University of Mombasa, Mombasa, Kenya \\ ${ }^{2}$ Electrical and Electronics Department, JKUAT, Nairobi, Kenya
}

\section{Email address:}

mogaka.Lucas@gmail.com (L. O. Mogaka),dkmurage25@yahoo.com (D. K. Murage), michaelsaulo@yahoo.com (M. J. Saulo)

\section{To cite this article:}

Lucas Ongondo Mogaka, D. K. Murage, Michael Juma Saulo. Rotating Machines Based Islanding Detection Using Fuzzy Logic Method Analysis. International Journal of Energy and Power Engineering. Vol. 4, No. 5, 2015, pp. 311-316. doi: 10.11648/j.ijepe.20150405.21

\begin{abstract}
An electric rotating machine can be defined as any form of apparatus which has a rotating member and generates, converts, transforms, or modifies electric power, such as a motor, generator, or synchronous generator. Although there are many variations, the two basic rotating machine types are synchronous and induction machines. The recent increasing use of rotating machines among other distributed generators is due to a number of advantages including peak shaving, improvement of the quality of power and reliability, power efficiency, environmental friendliness among others. Despite the above mentioned benefits of distributed power generation in the power grid, they have one major drawback, unintentional islanding. If this islanding condition is not detected in time or goes undetected, the distributed generator loses synchronism with the rest of the utility supply. This may lead to out of phase reconnection of the two systems and thus destroying the distributed generators and even lead to a total blackout in the power system. Again, upon the occurrence of an island, rotating machine based generators have another possible consequence of self-excitation. There is therefore need of fast detection of islanding condition especially when rotating machine based generators are integrated into the main power grid. There are many islanding detection methods and each has its merits and demerits. Their usage depends on certain factors including type of distributed generation in consideration and cost of implementation. Furthermore, the rotating machine based generators have the capability of sustaining an island. This makes the islanding detection and protection of these generators a bit challenging when compared with inverter based generators. This paper presents a passive islanding detection method, fuzzy logic algorithm, particularly on rotating machine based generators and its results analyzed under different conditions. After this analysis, it is concluded that the proposed method for islanding detection for rotating machine based generators is robust and accurate when implemented in the distribution network. This is because fuzzy logic control helps to improve the interpretability of knowledge-based classifiers through its semantics that provide insight in the classifier structure and decision-making process over crisp classifiers.
\end{abstract}

Keywords: Fuzzy Logic Control, Rotating Machines, Islanding Detection

\section{Introduction}

The increase of distributed resources in the electric utility systems is being witnessed currently due to recent and ongoing technological, social, economical and environmental aspects [1]. This trend has significantly brought many psitive and negative effects to both the power system infrastructure and the electric power market at large.

The Distributed Generation (DG) technologies can be broadly and generally categorized into inverter-based or rotating machine-based generation, that is both synchronous and induction machine based generators [2]. There is a variety of rotating machine-based DG technologies in use currently.
These include and not limited to; Small hydraulic units, with and without governor, driving synchronous generators with automatic voltage regulators, diesel units with governors and voltage regulators, wind turbines connected to the system through directly coupled induction generators, and Wind turbines connected to the system through doubly-fed induction generators [3].

The integretion of the distributed generation to the power system has a number of advantages which favours its use. These include peak saving when most loads are connected into the system, saving on the costs of upgrading the transmision and distribution part of the grid, environmental friendliness of most DGs among other merits. 
However, despite these merits and the continued use of DGs in the power grid, it has some drawbacks. These include; posing of health and safety hazards to the maintainance personnel, it creates and compromises power quality and associated problems for customers load, out of phase re-connection of the recloser switches and most importantly unintentional islanding. Islanding condition occurs when the DG continues to power a part of the grid system even after the connection to the rest of the system has been lost, either intentionally or unintentionally. Thus, this calls for accurate and efficient methods of detecting the islanding condition for the said DG to operate within required conditions.

As per IEEE standard 1547-2003, the distributed generators must sense any unplanned power grid formed and trip it within two seconds, failure to which may lead to several problems in terms of power quality, safety and operational problems [11]. To curb this, there are a number of islanding detection methods being used currently and each has its advantages and disadvantages. Hence, there are some parameters oftenly used to check the suitability of any given islanding detection method. These include; reliability of the method used, its impact on the power grid, operation time and cost effectiveness to both the DG owner and the power utility companies [2]

There are a number of islanding detection methods being used currently and each has its advantages and disadvantages. Hence, there are some parameters oftenly used to chech the suitability of any given islanding detection method. These include; reliability of the method used, its impact on the power grid, operation time and cost effectiveness to both the DG owner and the power utility companies [2].

\section{Islanding Detection Methods Classification}

Islanding detection methods can be broadly classified into local and remote islanding detection methods. The remote methods include power line communication (PLC) and supervisory control and data acquisition (SCADA) methods. These methods do not have Non-Detection Zones (NDZ) and are more reliable in their usage compared with the local methods. However, the major weakness of these methods is that they are more expensive to implement thus making them uneconomical for small systems. The NDZs are common problems in the islanding detection in power systems and can be defined as a loading condition for which an islanding detection method would fail to operate in a timely manner [4].

The local islanding detection methods are further categorized into active and passive islanding detection methods. Passive techniques are based on measurement of the information at the local site and comparing it with the preset value in determining the occurrence of an island, such as under or over frequency, under or over voltage, voltage phase jump, voltage unbalanced, total harmonic distortion, rate of change of frequency, vector surge, phase displacement monitoring, rate of change of generator power output, comparison of rate of change of frequency [1] among others.
These methods include; the rate-of-change of power signal, the rate-of-change of voltage and change in power factor, the vector surge technique, the rate-of-change of frequency, the phase-shift method, the harmonic impedance estimation technique [5]. Some of the merits of these islanding detection methods include; they are cheap and easy to implement and have no effect on the system when used. It also works pretty well when the mismatch between the generated power and the size of the load is very large.

The parameters typically used to detect islanding conditions in the passive islanding detection method are frequency and voltage. The first discussed passive method is the Over/under voltage and over/ under frequency (OUV/OUF), which is one of the oldest used passive anti-islanding detection technique. These techniques basically monitor the systems voltage and frequency in order to decide whether or not an islanding has taken a place [10]. The under/over voltage (UVP/OVP)and under/overfrequency (UFP/OFP) is the oldest technique adapted to protection the distribution system. The protection relays for this technique are placed on a distribution feeder to determine the various types of abnormal conditions. UVP/OVP and UFP/OFP are used to monitor of the grid voltage/frequency exist the limits im posed by the relevant standards [4] Thresholds for UOV and UOF.

On the other hand, active islanding detection methods have very small non-detection zones compared to passive methods. However, they introduce external signals into the power system thus lowering the power quality. According to these methods, some signals are added into the system which aid in detecting islanding condition. These signals have no effect when the distributed generator is in parallel operation with the mains; but they are quickily detected in case of loss of the main grid. Some of active methods in use currently include; positive feedback for active and reactive power loops in governor and excitation system of synchronous DGs, injection of a negative sequence of current through the interface Voltage-Sourced Converter (VSC) [6], Sandia frequency and voltage shift methods and harmonic amplification factor, which is based on the voltage change at the Point of Common Coupling (PCC) [7].

Generally, in islanding detection, two major steps are involved. This include the extraction of features from the signal and then classification of the extracted features for islanding dection. This is well explained in the figure below.

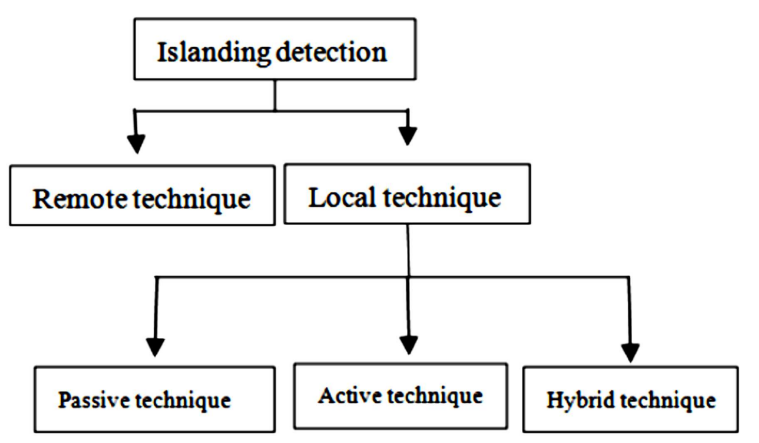

Figure 1. General islanding detection steps. 
The rest of this paper is organized as follows; section 3 discusses the theories of fuzzy logic algorithm used in islanding detection, section 4 explains the methodology that is used in this study, the results of the study are discussed in section 5 and finally the conclusions are drawn in section 6 .

\section{Fuzzy Logic Controller}

A fuzzy logic controller is a control algorithm based on several linguistic control rules and it is used to analyze continuous signals. The fuzzy rule base has the ability to handle more uncertainties in the signal being analyzed that fall along the slope of the fuzzy trapezoidal membership function unlike the crisp classifiers like decision tree which have sharp boundaries, and large data base. Thus, the superior approximation capabilities of the fuzzy systems over crisp classifiers help to develop algorithms that meet the real time application with wide range of uncertainties. Hence the fuzzy logic controller can easily and accurately be used in islanding detection for rotating machine based generators. Fuzzy logic system has also an ability to express non-linear input and output parameters into a set of qualitative IF THEN rules.

Some of the recent applications of fuzzy logic in islanding detection are as follows; in [8], fuzzy logic was introduced from the transformation of decision tree, where the combination of fuzzy membership functions (MFs) and the rule base were used to develop the fuzzy rule base. This technique was easy to implement for online islanding detection and could handle uncertainties such as noise. In [9], however, the band pass filter was used to replace the function of discrete wavelet transform and still worked out pretty well.

Basically a Fuzzy inference system (FIS) is composed of five functional blocks as shown in Figure 2 below. These include fuzzification interface, defuzzification interface, decision making unit, data base and rule base blocks.

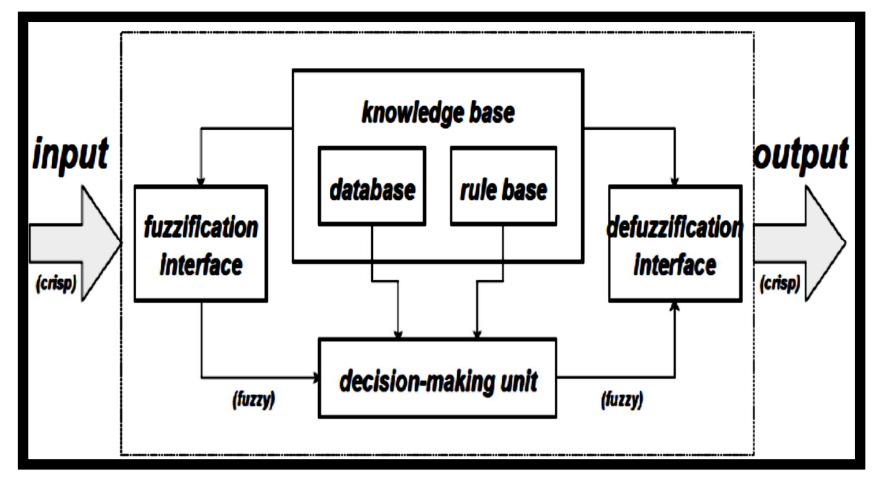

Figure 2. Fuzzy inference system [1].

\section{Methodology}

The figure 3 below was used for this analysis.

\section{Load data}

Nominal ph-ph voltage: 400 vrms, Nominal frequency: 50 Hz, Active power: $500 \mathrm{kw}$, Configuration: Y (grounded)

Syncronous machine (Generator) data

Rotor type: salient pole, Nominal power: 2MVA, Voltage: 400vrms, Frequency: 50hz, Field current: 100A

Grid (3-phase source) data

Phase to phase rms voltage: $25 \mathrm{kv}$, Frequency: $50 \mathrm{hz}$, Internal connection: $\mathrm{Yg}$, 3-phase short circuit level at base voltage: $100 \mathrm{mva}, \mathrm{X} / \mathrm{R}$ ratio: 7

In this system, the following three main features are chosen and measured to be used in the algorithm. These include frequency deviation, rate of change of power (ROCOP) and rate of change of frequency (ROCOF). However, under normal circumstances, there are eleven features that can be measured and used in islanding detection. These include; the frequency deviation, the voltage deviation, rate of change of frequency, rate of change of voltage, rate of change of power, rate of change of frequency over power, the total harmonic distortion of the current, total harmonic distortion of the voltage, the power factor deviation under, the absolute value of the phase voltage times power factor and the gradient of the voltage times power factor. Among all these features, only the three mentioned above are sufficient in islanding detection.

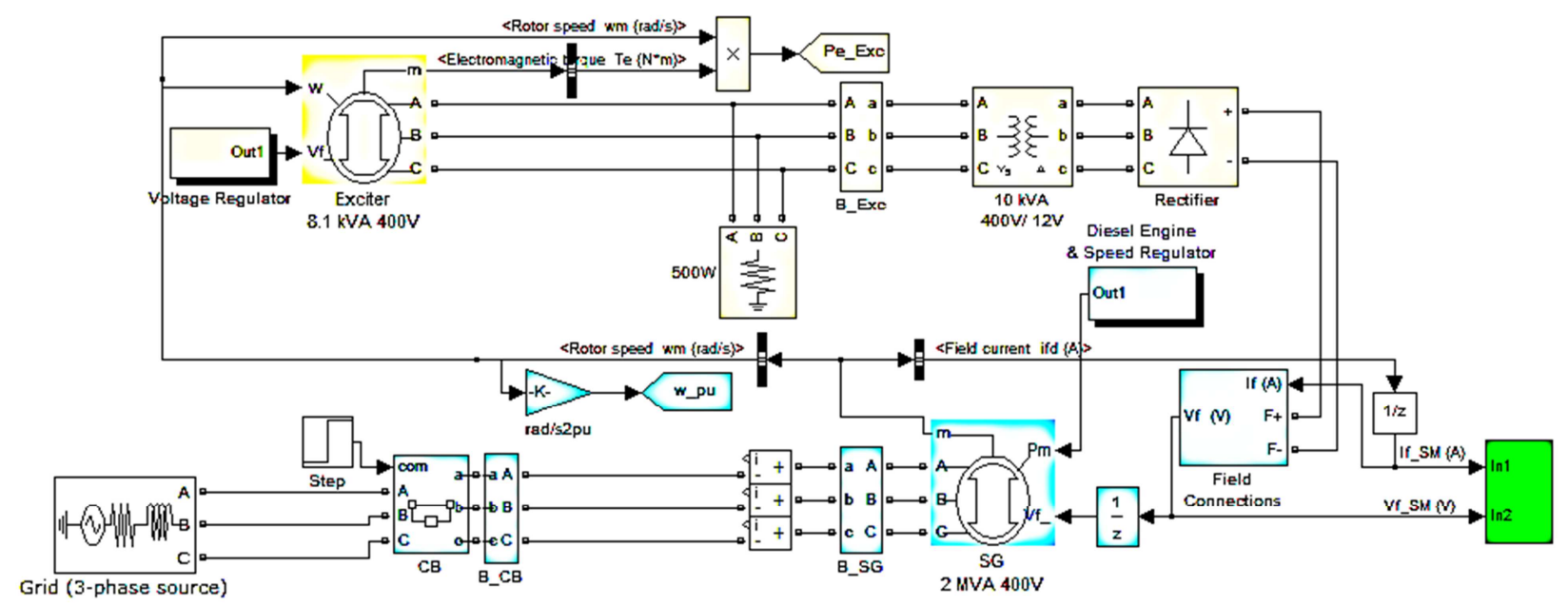

Figure 3. System used for the analysis. 


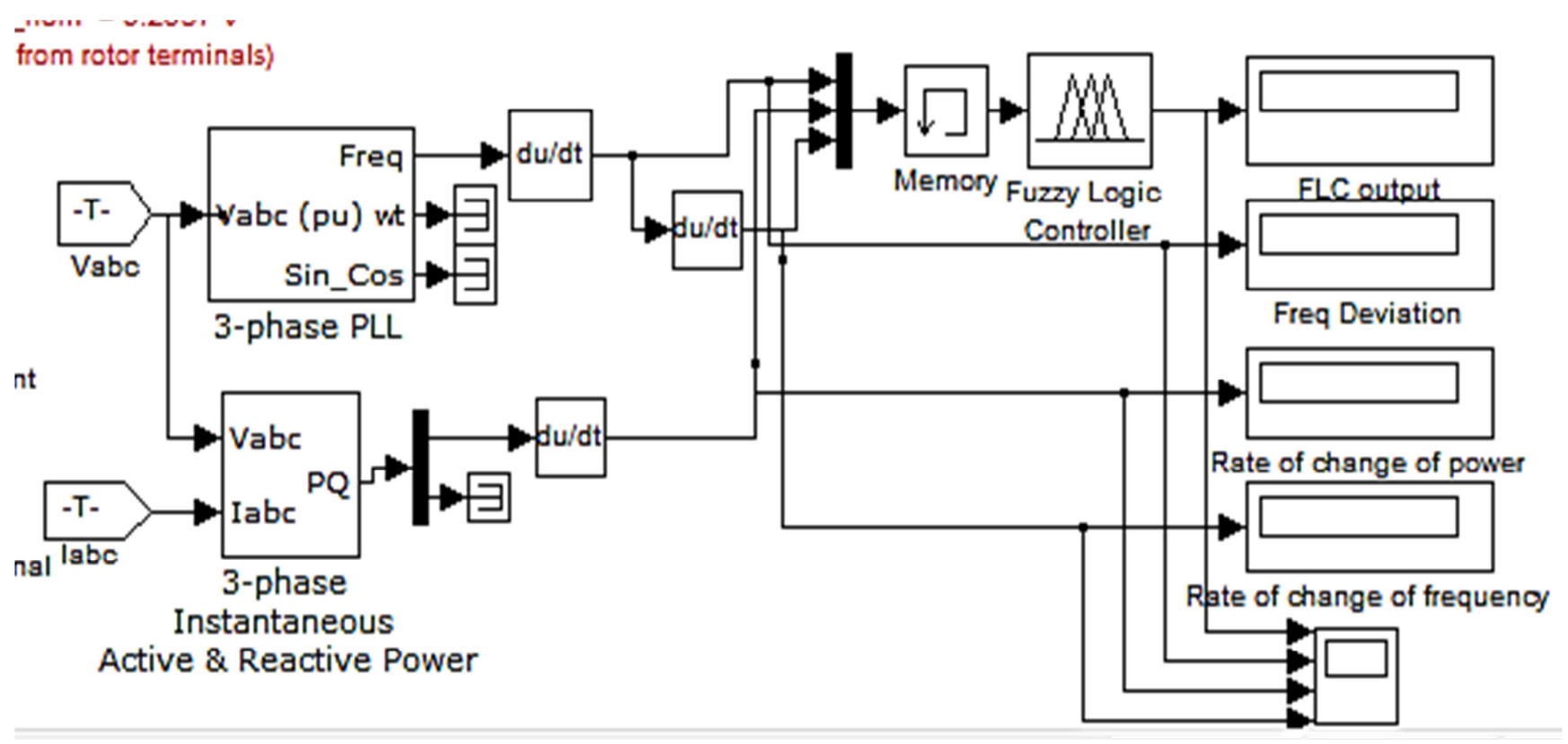

Figure 4. Fuzzy Inference system for islanding detection.

The above mentioned features are extracted under different islanding and non-islanding conditions of the network. That is, when the circuit breaker $(\mathrm{CB})$ is both closed and also tripping it to create the condition of islanding of the distributed generator while supplying the bus loads at the PCC. The extracted features are then subjected to fuzzy logic algorithm as shown in the figure below to determine the islanding and no islanding condition.

In this study, Mamdani fuzzification model is used in implementing the rules and centroid method is used in defuzzification of the output as shown in figure 5 below.

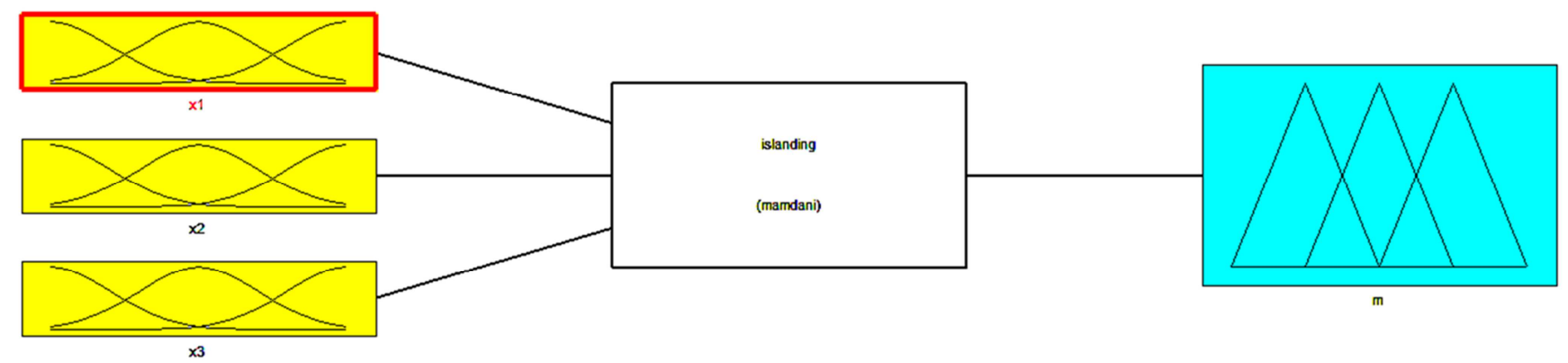

Figure 5. Fuzzy inference system showing mamdani fuzzification.

\section{Results and Discussion}

After setting up the model as shown above and simulating, the results of the analysis are as follows. First, the algorithm was able to distinguish islanding condition from non-islanding condition as shown in figure 6 below.

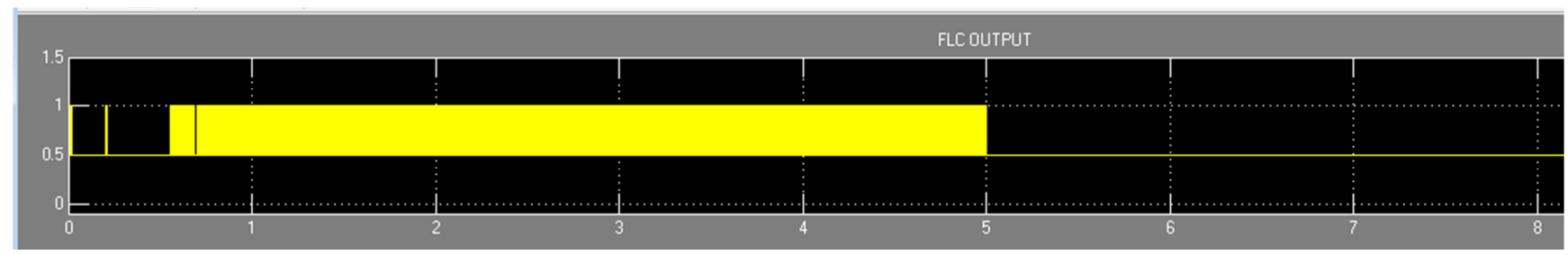

Figure 6. FLC output.

Then the frequency measurement was done and the result is as shown in figure below. As it can be seen, the frequency varies from the normal on the $5^{\text {th }}$ second as soon as the CB is opened. 


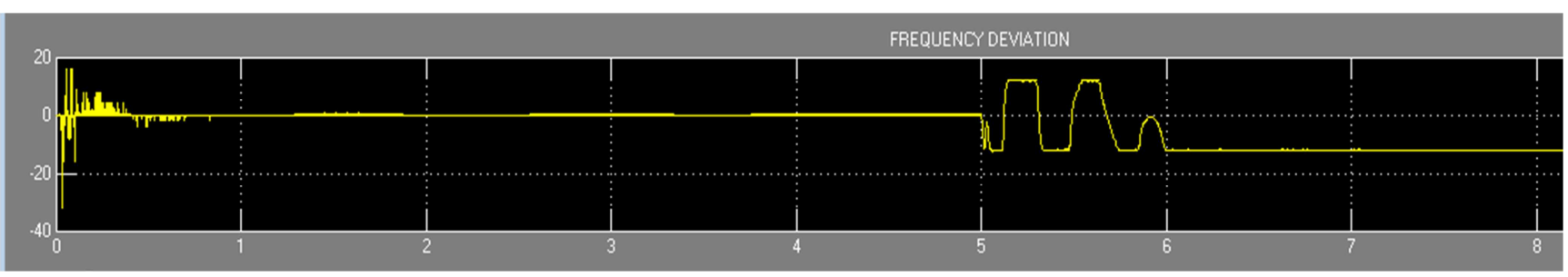

Figure 7. Frequency deviation measurement.

The rate of change of power (ROCOP) was also measured and its result is as shown in figure 8 below. It is noted that there is a sharp change on the $5^{\text {th }}$ second when the CB opens to create an island. Then later return to normal position. This is due to the voltage regulator which restores the system back immediately. ROCOP is normally used to measure the impact the active power variations have on frequency and the voltage of the system. When the DG is operating with mains, the system the impact is usually small. However, this is not the case when the DG is operating in an island.

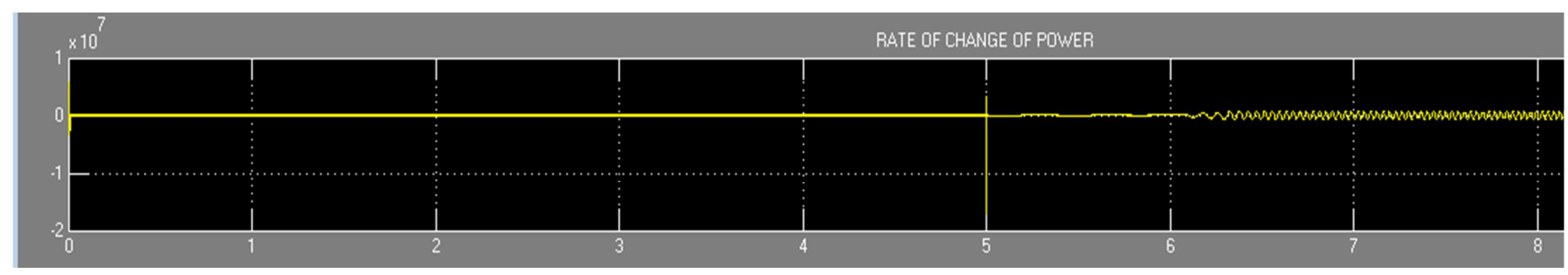

Figure 8. Rate of change of power.

Lastly, the rate of change of frequency was measured and the result was as shown in figure 9 below. Unlike frequency deviation, there is no significant change when the $\mathrm{CB}$ is opened to create an island.

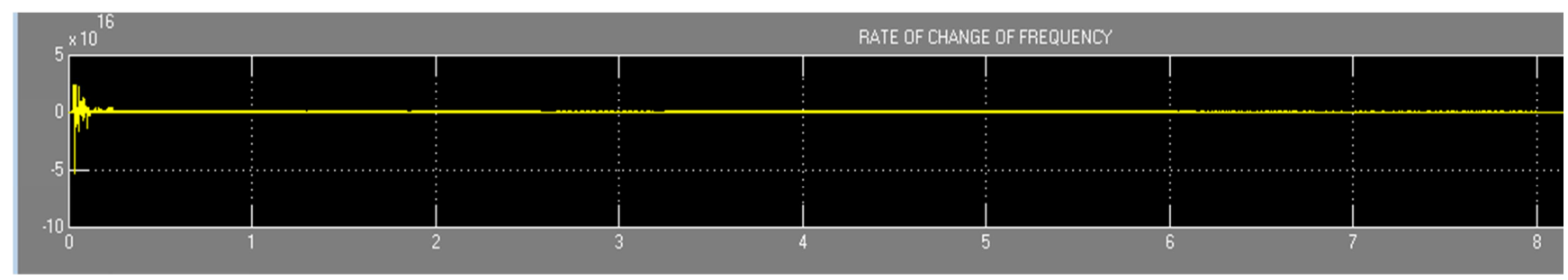

Figure 9. Rate of change of frequency.

\section{Conclusion}

This proposed method for islanding detection for rotating machine based generators is robust and accurate when implemented in the distribution network. This is because fuzzy logic control helps to improve the interpretability of knowledge-based classifiers through its semantics that provide insight in the classifier structure and decision-making process over crisp classifiers [5]. Another advantage of fuzzy logic is its ability to handle more noise falling along its trapezoidal membership functions and it does not have sharp boundaries like other crisp classifiyers like decision tree and others. This method is therefore suitable in developing relays for real time islanding and non-islanding detection in a large power grids.

\section{Acknowledgement}

The authors would like to express the greatest gratitude to the Technical University of Mombasa for the continued support from time to time when required.

\section{References}

[1] S. Noradin and G. Behrooz, "Adaptive neuro-fuzzy inference system (ANFIS) islanding detection based on wind turbine simulator," International Journal of Physical sciences, vol. 8, no. 27, pp. 1425-1436, 23 July 2013.

[2] A. Etxegarai, I. Zamora, P. Eguia and L. Valverde, "Islanding detection of synchronous distributed generators," in International Conference on Renewable Energies and Power Quality, spain, 28th to 30th March, 2012.

[3] B. A. Ozeer, G. Hernandez-Gonzalez and T. H. and EL-Fouly, "GuilleDistributed Generation Analysis Case Study 5 Investigation of Passive Anti-Islanding Detection for Rotating Machine-based DG Technologies," Varennes Research Centre, Canada, 2012.

[4] H. Vahedi, R. Noroozian, A. Jalilvad and G. B. Gharehpetian, "A new method for islanding detection of inverter based distributed generation using DC-link voltage control," IEEE Transaction on power delivery, vol. 26, no. 2, pp. 1176-1186, 2011. 
[5] K. M. Shareef, K. H. Reddy and K. S. Kumar, "Islanding detection in Distributed Generation by using Fuzzy Rule based approach," Journal of Electrical and Electronics Engineering, vol. 2, no. 2, pp. 30-36, July-Aug 2012.

[6] B. Bahrani, H. Karimi and R. Iravani, "Non-Detection zone assessment of an active islanding detection method and its experimental evaluation," IEEE transaction on power delivery, vol. 26, no. 2, pp. 517-525, 2011.

[7] M. Bakhshi, R. Noroozian and G. B. Gharehpetian, "Islanding detection of synchronous machine based DGs using average frequency based index," Iranian journal of electrical and eletronic engineering, vol. 9, no. 2, pp. 94-106, June 2013.

[8] S. Samanta, k. El-arroudi, G. Joós and k. I., "A fuzzy rule-based approach for islanding detection in distributed generation," IEEE Transaction on Power Delivery, pp. 1427-33, 2010.
[9] J. Pham, N. Denboer, N. Lidula, G. Member, N. Perera and A. Rajapakse, "Hardware implementation of an islanding detection approach based on current and voltage transients.," Electrical power and energy conference (EPEC), pp. 152-157, 2011.

[10] H. Zeineldin, E. El-Saadany, M. Salama, "AImpact of DG Interface Control on Islanding Detection and Nondetective Zones," IEEE Trans.on Power Del, vol. 21, no. 3, pp. 1515 1523, July 2006.

[11] Pukar Mahat, Zhe Chen, and Birgitte Bak-Jensen,, "Review on islanding operation of distribution system with distributed generation," International Conference on Electric Utility Deregulation and Restructuring and Power Technologies, Nanjing, China, p. 2743 2748, April 2008. 